\title{
UM PANORAMA DA QUALIDADE DOS ITENS ELABORADOS PARA O BANCO NACIONAL DE ITENS DA EDUCAÇÃO SUPERIOR NA EDIÇÃO DO ENADE DE 2019
}

\author{
Atair Silva de Sousa ${ }^{1}$
}

\begin{abstract}
RESUMO
Este artigo se propõe a discutir funcionalidades pedagógicas em uma visão panorâmica da qualidade dos Itens produzidos para o Banco Nacional de Itens (BNI) do Exame Nacional de Desempenho de Estudantes (ENADE) da edição de 2019. Os objetivos foram: descrever os procedimentos da produção de Itens para a prova do ENADE; analisar a eficiência da produção de Itens e; propor medidas pedagógicas que possam trazer melhorias no aproveitamento de Itens para o $\mathrm{BNI}$ ENADE. Foi realizada uma revisão bibliográfica documental e uma busca de dados e informações disponibilizadas pelo Instituto Nacional de Estudos e Pesquisas Educacionais (INEP). Os resultados mostraram eficiências positivas no aproveitamento de Itens para todos os cursos avaliados na edição do ENADE de 2019.
\end{abstract}

Palavras-chave: Avaliação da Educação Superior. Banco Nacional de Itens. ENADE.

\section{AN OVERVIEW OF THE OF THE QUALITY OF THE ITEMS DEVELOPED FOR THE NATIONAL BANK OF HIGHER EDUCATION ITEMS IN THE 2019 ENADE EDITION}

\begin{abstract}
This paper proposes to discuss pedagogical features in a panoramic view of the quality of Items produced for the National Bank of Items (BNI) of the National Examination of Student Performance (ENADE) for the 2019 edition. The objectives were: to describe the procedures of the production of Items for the ENADE exam; to analyze the efficiency of the production of Items and; to propose pedagogical measures that can bring improvements in the use of Items for the BNI-ENADE. A documental bibliographic review was carried out and a search for data and information made available by the National Institute for Educational Studies and Research (INEP). The results showed positive efficiencies in the use of Items for all courses evaluated in the 2019 edition of ENADE.
\end{abstract}

Keywords: Evaluation of Higher Education. National Bank of Items. ENADE.

\footnotetext{
1 Doutorando em Educação pela Universidade de São Paulo (USP), Programa de Pósgraduação em Educação - Área de concentração: Estado, Sociedade e Educação - Brasil. Orcid iD: http://orcid.org/0000-0002-1355-8797. E-mail: atair.sousa@usp.br
} 


\section{UNA VISIÓN GENERAL DE LA CALIDAD DE LOS ARTÍCULOS PREPARADOS PARA}

\section{EL BANCO NACIONAL DE ARTÍCULOS DE EDUCACIÓN SUPERIOR EN LA EDICIÓN} 2019 DE LA ENADE

\section{RESUMEN}

Este artículo propone discutir las características pedagógicas en una visión panorámica de la calidad de los ítems producidos para el Banco Nacional de Ítems (BNI) del Examen Nacional de Desempeño Estudiantil (ENADE) para la edición 2019. Los objetivos fueron: describir los procedimientos de producción de ítems para el examen ENADE; analizar la eficiencia de la producción de ítems y; proponer medidas pedagógicas que puedan aportar mejoras en el uso de ítems para la BNIENADE. Se realizó una revisión bibliográfica documental y una búsqueda de datos e información disponible en el Instituto Nacional de Estudios e Investigaciones Educativas (INEP). Los resultados mostraron eficiencias positivas en el uso de ítems para todos los cursos evaluados en la edición 2019 de la ENADE.

Palabras clave: Evaluación de la Educación Superior. Banco Nacional de Artículos. ENADE.

\section{INTRODUÇÃO}

O Banco Nacional de Itens (BNI) foi criado pelo Instituto Nacional de Estudos e Pesquisas Educacionais (INEP) para fornecer insumos para as diversas avaliações que desenvolve, assegurando acesso a ltens de qualidade, elaborados e revisados para cada instrumento de medição. 0 INEP realiza chamadas públicas para a construção de uma rede de colaboradores interessados em elaborar e revisar Itens para $\bigcirc \mathrm{BNI}$, constituindo o Banco de Colaboradores do BNI para cada avaliação ou exame em desenvolvimento (INEP, 2019a). Neste artigo a abordagem está focada no BNI-ENADE, ou seja, no Banco Nacional de Itens da Educação Superior.

O primeiro parágrafo do art. $5^{\circ}$ da Lei de criação do Sistema Nacional de Avaliação da Educação Superior (SINAES) - Lei n 10.861, de 14 de abril de 2004 - traz em seu âmbito, o vínculo do Exame Nacional de Desempenho de Estudantes (ENADE) com esse sistema de avaliação (BRASIL, 2004a). O objetivo do ENADE é avaliar a trajetória dos estudantes dos cursos de graduação, em relação aos conteúdos programáticos, habilidades e competências adquiridas em sua formação. O processo avaliativo desse 
exame é constituído por quatro instrumentos que auxiliam na avaliação da qualidade da Educação Superior e na busca de subsídio para políticas de melhoria, a saber: a prova, o questionário do estudante, o questionário de percepção da prova e o questionário do coordenador de curso (INEP, 2019d). No âmbito da prova do ENADE, o BNI-ENADE se caracteriza como um instrumento das diretrizes da avaliação da Educação Superior e, por conseguinte, inserido nas atribuições direcionadas pela lei de criação do SINAES.

Diante do exposto, o presente estudo busca responder a seguinte questão: que medidas pedagógicas podem ser sugeridas e/ou adotadas, nos cursos de capacitação oferecidos pela Coordenação Geral do ENADE (CGENADE) do INEP aos docentes elaboradores de Itens, para contribuir com melhorias na eficiência do BNI-ENADE?

Para este estudo, a eficiência é definida como: a razão entre o número de Itens inseridos no BNI-ENADE para cada curso ou área naquela edição do ENADE e o número de Itens elaborados para cada curso ou área. A equação a seguir representa o modelo de como efetuar o cálculo da eficiência: $\mathrm{E}=\frac{(\mathrm{Ia}-\mathrm{Ip})}{\mathrm{Ie}}$, na qual: "E" representa a eficiência; "Ia" o número de Itens aceitos (aprovados); "IP" o número de Itens selecionados para prova e; "le" o número de Itens elaborados. Este é um cenário esperado, embora possa acontecer o fato de que, dentre os Itens aceitos não seja possível extrair os 30 Itens de prova, ou no caso da Formação Geral 10 Itens. Neste caso, buscam-se Itens existentes no BNI-ENADE para completar o número de Itens de prova.

A justificativa para a investigação desse assunto está relacionada ao fato do autor ter como base a relação profissional com o tema/problema, tendo em vista a atuação dele na CGENADE do INEP. Além disso, docentes que se dispõem a participar das oficinas de elaboração de Itens para o BNIENADE, acenam com dificuldades em construir Itens com os padrões exigidos para este banco de Itens. Com isso, espera-se apontar alternativas na condução de ações afirmativas que resultem em um processo que torne 
mais efetiva a participação dos elaboradores de Itens para o BNI-ENADE, com impactos positivos nos resultados dos Itens elaborados. Assim, provocando reflexos positivos na eficiência dos Itens produzidos para este banco de Itens e, assim resultando no aprimoramento do BNI-ENADE.

Neste trabalho são apresentados os principais pontos explicativos na elaboração de Itens para a prova do ENADE. Com isso, para este estudo, o objetivo específico foi: propor medidas pedagógicas que possam trazer melhorias no aproveitamento de Itens para 0 BNI-ENADE. Neste trabalho utilizou-se um método de estudo qualitativo/quantitativo. Realizou-se uma análise documental com a leitura e análise de informações disponibilizadas em sítios oficiais, como por exemplo, do Ministério da Educação (MEC) e do INEP, que tratam da legislação vigente sobre a avaliação da qualidade da Educação Superior no Brasil.

Este trabalho está organizado em quatro seções, além desta introdução. Na segunda seção são descritas as rotinas e processos que circundam o BNI e discutidos os processos do BNI-ENADE. Na terceira seção são apresentados os procedimentos metodológicos. Na quarta seção é apresentada uma análise, discussão e conclusão dos resultados, apontando propostas de intervenções pedagógicas. Na última seção são realizadas as considerações finais, fazendo uma síntese deste estudo.

\section{PROCEDIMENTOS METODOLÓGICOS}

Para este estudo o método de pesquisa utilizado foi do tipo qualitativo/quantitativo. O método qualitativo está em relevo pelo predomínio de análises, diálogos e discussões das assertivas contextualizadas aos aspectos pedagógicos do BNI-ENADE. Os dados coletados são secundários e de natureza quantitativa - valores inteiros relativos ao número de Itens do BNI-ENADE do INEP 2019.

A fonte de dados quantitativos utilizados neste estudo teve sua origem em Relatório de 2019 do INEP, disponibilizados pela Ouvidoria do INEP, cuja solicitação teve como número de protocolo: 23546.025418/2021-09, via portal do fala.br. 
Foram utilizadas ferramentas da estatística descritiva simples por motivo de coleta de dados que tem a sua natureza quantitativa, sejam na elaboração de tabelas, quadros, dados percentuais ou processos de contagem. Os dados são do tipo secundário por terem sido produzidos, seja pelo INEP, seja por autores da área educacional.

Com esse entendimento, tomou-se como objeto a análise de dados e informações no ano de 2019, com a premissa de melhor mapear as ações previstas no processo de capacitação dos colaboradores do BNI-ENADE. Observando-se as especificidades da base, optou-se pela utilização dos dados do INEP, em função desse órgão apresentar coletas de dados de todo o processo e atividades do BNI-ENADE.

Os dados coletados foram dispostos em tabelas e gráficos transformados em valores inteiros absolutos, tanto do quantitativo de Itens quanto das percentagens relativas às eficiências do aproveitamento de Itens. Este procedimento pode facilitar futuras comparações entre a edição do ano de 2019 e as que o sucederem. Neste caso, visualizar a evolução de Itens aprovados, se de fato, evoluíram em quantidade e qualidade.

\section{O BNI COMO PROCESSO DE QUALIDADE NA INSTRUMENTAÇÃO DA AVALIAÇÃO DA EDUCAÇÃO}

O BNI define-se, como uma coleção de Itens de testes de natureza específica - organizada segundo determinados critérios - disponíveis para a construção de instrumentos de avaliação (BRASIL, 2020). A manutenção do BNI depende da entrada constante de Itens de qualidade. Para tanto, educadores e pesquisadores da educação brasileira são chamados a colaborar nessa construção, elaborando Itens que possam fazer parte desse banco.

O guia de elaboração e revisão de Itens apresenta as orientações do INEP para a construção e revisão de Itens para testes de avaliação em larga escala, considerando a literatura especializada na área e, se estrutura da seguinte forma: definições e conceitos; estrutura do Item de múltipla escolha; 
etapas para elaboração de Item; especificações para apresentação do Item; etapas de validação de Item; protocolo de revisão de Item (INEP, 2019c).

As avaliações em larga escala distinguem-se das avaliações internas, sendo que estas são elaboradas pelo professor ou pela própria Instituição para avaliar e propor alternativas no âmbito da sala de aula ou da Instituição. Enquanto isso, as avaliações em larga escala são elaboradas por um órgão externo à Instituição com a finalidade de fazer juízos de valor e propor alternativas em âmbito mais amplo que o da Instituição (INEP, 2020). É neste contexto das avaliações de larga escala que a implementação do BNI se apresenta como uma solução para a elaboração e montagem das provas. No quadro 1 são apresentados os instrumentos avaliativos que utilizam o BNI.

Quadro 1 - Processos dos instrumentos avaliativos do BNI

\begin{tabular}{|c|c|}
\hline \multicolumn{2}{|l|}{ PROCESSO DO BNI } \\
\hline INSTRUMENTO AVALIATIVO & $\begin{array}{c}\text { NÍVEL } \\
\text { EDUCACIONAL }\end{array}$ \\
\hline $\begin{array}{l}\text { Provinha Brasil; Sistema Nacional de Avaliação da } \\
\text { Educação Básica-SAEB. }\end{array}$ & Educação Básica \\
\hline Programa Internacional de Avaliação de Alunos - PISA. & Educação Básica \\
\hline Exame Nacional do Ensino Médio - ENEM. & Educação Básica \\
\hline Exame Nacional de Desempenho de Estudantes - ENADE. & $\begin{array}{l}\text { Educação } \\
\text { Superior }\end{array}$ \\
\hline $\begin{array}{l}\text { Exame Nacional de Certificação de Competências de } \\
\text { Jovens e Adultos - ENCCEJA. }\end{array}$ & Educação Básica \\
\hline Revalidação dos Diplomas Médicos - REVALIDA. & $\begin{array}{l}\text { Educação } \\
\text { Superior }\end{array}$ \\
\hline $\begin{array}{l}\text { Certificado de Proficiência na Língua Brasileira de Sinais - } \\
\text { PROLIBRAS. }\end{array}$ & Educação Básica \\
\hline $\begin{array}{l}\text { Certificado de Proficiência em Língua Portuguesa - CE } \\
\text { BRAS. }\end{array}$ & Educação Básica \\
\hline
\end{tabular}

Fonte: Elaborado pelo autor.

Uma atividade necessária para que essas avaliações aconteçam é a manutenção de um banco de Itens que ofereça subsídios para construir os testes. A existência de um BNI no INEP é necessária para que se tenha uma quantidade expressiva de Itens com comprovada qualidade técnico- 
pedagógica e psicométrica para comporem os testes de uma avaliação em larga escala. O BNI define-se, portanto, como uma coleção de Itens de testes de natureza específica - organizada segundo determinados critérios disponíveis para a construção de instrumentos de avaliação. A manutenção do BNI depende da entrada constante de Itens de qualidade. Para tanto, educadores e pesquisadores da educação brasileira são chamados a colaborar nessa construção, elaborando Itens que possam fazer parte desse banco. Em atividades dessa natureza, a experiência docente é de fundamental importância para que se possam elaborar itens em consonância com o contexto educacional (INEP, 2010).

O BNI da Educação Superior, criado em 2010 tem por objetivo reunir questões de qualidade técnica que permitam ao INEP avaliar por meio do exame o conhecimento dos estudantes em relação aos conteúdos programáticos, habilidades e competências previstas nas Diretrizes Curriculares Nacionais (DCNs) dos cursos de graduação. O INEP busca qualificar o exame com a construção de Itens elaborados por profissionais experientes. O BNI é um sistema importante na construção dos instrumentos avaliativos do INEP. Isso porque fornece a segurança necessária ao processo de construção das provas, confiabilidade e garante maior participação da comunidade acadêmica na construção dos Itens (INEP, 2019e).

Para Soares; Hora; Caseiro (2016, p. 5) "a criação, implementação e gestão do BNI-ENADE foi uma iniciativa do INEP para possibilitar a melhoria dos processos que envolvem a elaboração dos instrumentos de avaliação aplicados neste Exame". Este banco permitiu a ampliação da participação da comunidade acadêmica nas diversas etapas de construção dos instrumentos, além de aperfeiçoar o investimento na elaboração de Itens.

O ano de 2010 é um momento importante em ações desenvolvidas voltadas para a composição da prova do ENADE, tendo em vista que foi nesse ano a ocorrência da implantação do BNI-ENADE. Segundo Campos (2013) a criação desse banco se deu no trâmite institucional. A autora se refere ao BNI como um instrumento institucional, modelado para além da produção de Itens para comporem as provas. Ela defende que o BNI possui 
uma dupla missão tal que, "[...] é ao mesmo tempo um banco de Itens, com um banco de elaboradores e revisores de Itens. No caso da Diretoria de Avaliação da Educação Superior (DAES), este último tem a nomenclatura de Cadastro de Elaboradores e Revisores de Itens da Educação Superior CERES" (CAMPOS, 2013, p. 16-17).

O BNI-ENADE consiste de um sistema computacional no qual permanecem armazenados os Itens de testes de natureza específica que podem ou não ser utilizados nas provas do ENADE realizadas pelo INEP. Estes Itens são organizados seguindo critérios estipulados por cada edição do exame (CAMPOS, 2013). Este banco é um acervo de Itens elaborados a partir de matrizes de conteúdo, competências e habilidades, pré-definidos, que permitem a montagem de provas que buscam estimar com a maior precisão possível a proficiência dos estudantes com relação aos conteúdos de seus respectivos cursos de graduação, conforme previsto no art. $5^{\circ}$ da Lei $n^{\circ} 10.861 / 2004$ (INEP, 2019b).

Prevista nesta Lei, a Portaria $n^{\circ} 2.051$, de 9 de julho de 2004, em seu capítulo III art. $4^{\circ}$ e parágrafo único: a realização da avaliação das IES, dos cursos e do desempenho dos estudantes será responsabilidade do INEP, o qual instituirá Comissão Assessora de Avaliação Institucional (CAAl) e Comissão Assessora de Áreas (CAAs) para as diferentes áreas do conhecimento (BRASIL, 2004b).

Em função disso, as atribuições das CAAs adquiriram maior importância e dimensão à medida que passaram a ter maior participação na construção da prova. Desde então, O INEP tem buscado aprimorar o processo de composição das CAAs de forma a melhor caracterizar o perfil do profissional demandado para as atividades a serem realizadas, mas sem perder de vista sua adequação às demais peculiaridades do processo.

As etapas de trabalho vinculadas à operacionalização e manutenção do BNI-ENADE se iniciam, a cada ano, com a nomeação de uma CAA para a área de Formação Geral e para cada curso a ser avaliado. Essas comissões são formadas exclusivamente por docentes de IES, atendendo 
critérios de representatividade das 5 regiões do país e, ainda, de características administrativas (públicas e privadas).

Publicada a portaria de nomeação dos membros das CAAs, a primeira atividade presencial consiste na elaboração da portaria das diretrizes do ENADE referente ao curso e Formação Geral. Essa portaria possui um caráter relevante no contexto da prova do ENADE. Ela é composta por 8 artigos, sendo que, no âmbito da prova de Conhecimento Específico, os art. $5^{\circ}, 6^{\circ} \mathrm{e}$ $7^{\circ}$, definem a tridimensionalidade da matriz de prova. Para compor esta matriz de referência da prova do ENADE, os membros das CAAs devem definir um número de "perfis", um número de "recursos" e um número de "objetos de conhecimentos". Nos parágrafos seguintes é explicada e conceituada essa metodologia.

No art. $5^{\circ}$ da portaria do ENADE referente ao curso são definidos os "perfis" do egresso do referido curso. Nesse sentido, os membros da CAA devem selecionar em torno de 6 perfis principais que são esperados dos egressos do curso. No caso em questão, "perfil" tem o sentido de características que os estudantes desenvolveram ao longo do curso e, como egresso do curso, espera-se que tenham se apropriado de tais características. Assim, as palavras usadas para definir os "perfis" são palavras adjetivadas (adjetivos).

No art. $6^{\circ}$ são definidos os "recursos" (habilidades e competências) que os estudantes devem acionar para resolver problemas relacionados aos conhecimentos adquiridos ao longo de sua formação. Embora não seja estabelecido um número definido de "recursos", são sugeridos em torno de 12 recursos para comporem a matriz de prova. Portanto, o estudante ao ser avaliado em determinado Item da prova, mobiliza suas habilidades e competências para solucionar uma situação problema, seja na sua área de Conhecimento Específico ou de Conhecimentos Gerais. Ao mobilizar tais habilidades e competências, são propostas ações e, portanto, são palavras que verbalizam as ações (verbos).

No art. $7^{\circ}$ são definidos os "objetos de conhecimentos" (conteúdos) que foram desenvolvidos no processo de ensino e aprendizado ao longo da 
trajetória acadêmica do estudante. Conforme já mencionado, não há um número definido, mas em geral são usados em torno de 20 objetos de conhecimento para compor a matriz de prova. Com isso, estão apresentadas as três dimensões da matriz de prova do ENADE: "perfil"; "recurso"; e "objeto de conhecimento". Assim, para cada Item da prova é acionado um "perfil", um "recurso" e até três "objetos de conhecimentos".

As atividades dos membros das CAAs são delineadas ao longo dos processos de construção da prova. Segundo Soares; Hora; Caseiro (2016, p. 5) "as atribuições das CAAs dizem respeito à elaboração das diretrizes de prova, à concepção da matriz que dará origem aos instrumentos avaliativos, à seleção dos Itens que integrarão as provas e dos que serão armazenados no BNI". Além disso, os membros das CAAs devem elaborar análise dos relatórios de dados resultantes da aplicação do Exame. Para que os trabalhos das CAAs sejam desempenhados de acordo com os parâmetros de qualidade previamente definidos, o INEP capacita os membros dessas comissões no início de cada ciclo avaliativo.

É neste contexto bem definido das atribuições, que os membros das CAAs atuam em conjunto com a equipe da CGENADE, buscando um alinhamento de critérios e definições em cada etapa do processo, a fim de que, os resultados da eficácia desse trabalho conjunto, sejam revertidos em um produto final de qualidade, que é a prova do ENADE.

A partir da implementação do BNI-ENADE em 2010, são desenvolvidas várias ações no sentido de aperfeiçoar e atualizar os processos e metodologias de produção de Itens que comporão o BNI-ENADE. Tais ações vão sempre ao encontro de um melhor aproveitamento dos Itens produzidos pelos colaboradores. Uma dessas ações está centrada nos aspectos de inserção e aprimoramento das atividades desenvolvidas pelos colaboradores selecionados durante o curso de capacitação que eles realizam antes de iniciarem a produção de Itens.

Ao longo da última década foram estabelecidas etapas e sequências que apresentam uma lógica de procedimentos necessários à produção de 
Itens. O fluxograma (figura 1) apresenta um modelo didático do fluxo utilizado no BNI-ENADE.

Figura 1 - Fluxograma - Sequências do Fluxo BNI-ENADE

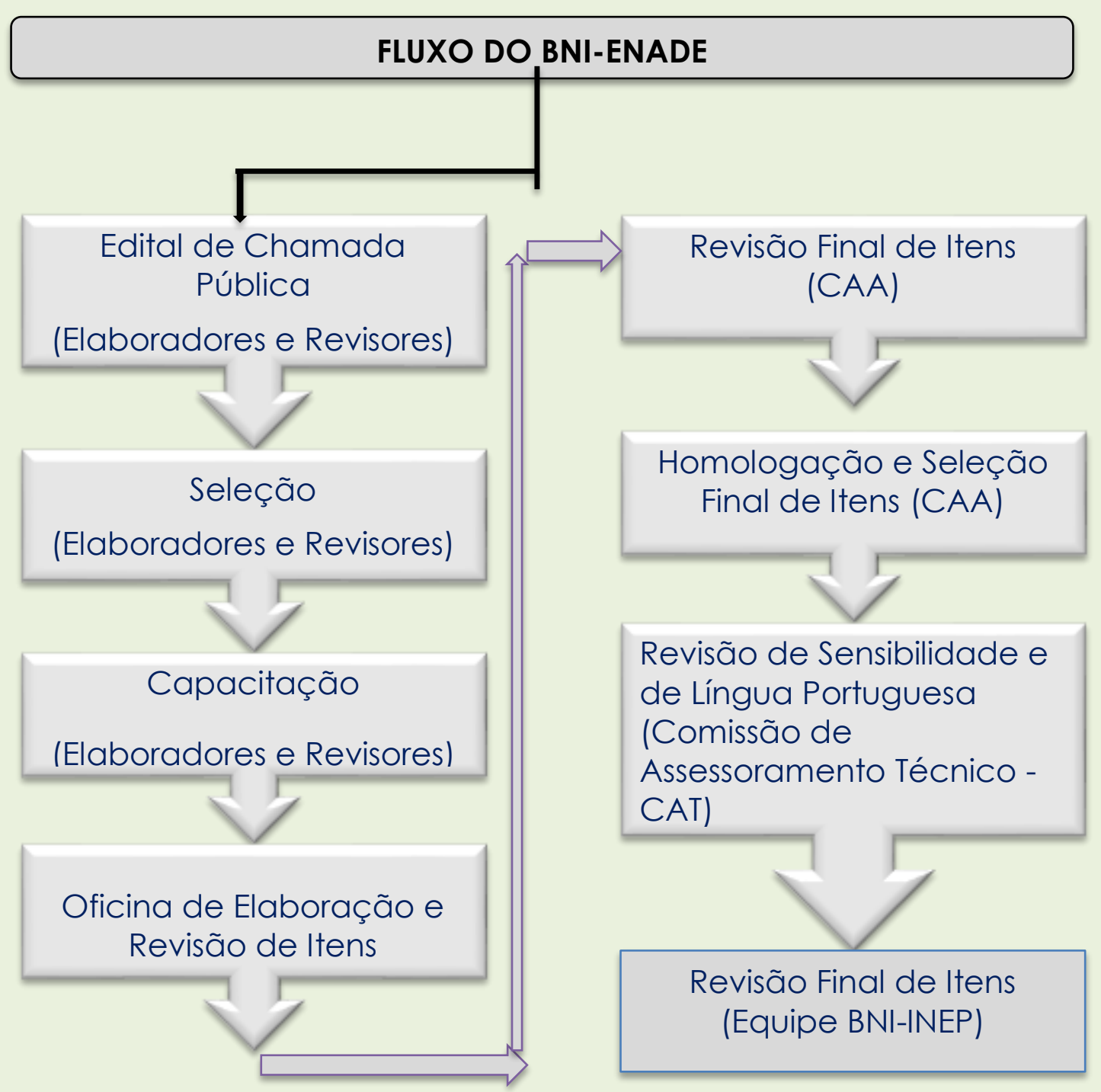

Fonte: Cerri (2016) adaptado.

Esse fluxo é expandido em definições e caracterização ao longo dos parágrafos a seguir. Neles, serão delineadas e definidas as etapas, os processos e os procedimentos necessários ao fluxo do BNI-ENADE. É importante salientar que, o proposto é fruto de estudo e aprimoramento constante, que foram sendo absorvidos à medida que as edições da prova do ENADE iam acontecendo, e o banco de Itens sendo abastecido a cada ano. 
Como se pode verificar no diagrama, o INEP efetua uma chamada pública convocando, a cada ano, docentes da Educação Superior interessados em participar do BNI-ENADE na condição de elaboradores e/ou revisores de Itens. Como já mencionado anteriormente, após a construção das diretrizes de prova de cada curso, O INEP publica um edital de chamada pública em que são apontados os procedimentos e os requisitos para a inscrição e seleção desses docentes interessados em participar do processo de elaboração e/ou revisão de ltens.

Um dos pré-requisitos para a seleção é que o docente esteja vinculado a uma IES e que lecione no curso ou, cursos afins, para o qual está se candidatando como elaborador e/ou revisor de Itens. Os inscritos são selecionados de acordo com requisitos previstos nesse edital de chamada pública observando estes critérios pré-estabelecidos. Após o processo de seleção, os colaboradores aprovados devem confirmar o interesse em participar nas atividades previstas no edital. A partir daí, tem-se o início do processo de capacitação dos docentes convocados e que confirmaram interesse em atuar no exame (SOARES; HORA; CASEIRO, 2016).

Para elaborar Itens de qualidade requer, além de conhecimentos específicos nos cursos que serão avaliados, também proficiência quanto às técnicas que envolvem sua construção. Com o propósito de produzir Itens que atendam ao padrão estabelecido para O ENADE, O INEP organiza um processo didático de capacitação para os elaboradores e revisores técnicopedagógicos. Somente os colaboradores que concluem esse processo de capacitação são convidados a participar das etapas seguintes.

Como já elucidado, a partir da matriz elaborada, são designadas encomendas de Itens aos elaboradores. Cada elaborador tem acesso somente às encomendas encaminhadas a ele e não à matriz completa da prova. A encomenda é um instrumento que orienta os elaboradores na elaboração de cada Item. Tanto a elaboração quanto à revisão de Itens são realizadas na modalidade à distância. Para tanto, uma conexão remota segura (VPN) é estabelecida entre os colaboradores e o sistema informatizado do BNI-ENADE, e por meio dela eles acessam o ambiente da 
Oficina de Elaboração e Revisão de Itens, em que interagem com as encomendas que Ihes foram encaminhadas. Uma vez finalizada essa etapa de revisão, os Itens são encaminhados à etapa para a revisão da CAA e, junto com os servidores da CGENADE realizam a revisão dos Itens encaminhados (SOARES; HORA; CASEIRO, 2016).

Nessa próxima etapa é realizada a carga de Itens e cada CAA analisa, seleciona e revisa os Itens de sua área de conhecimento. Aqueles Itens que apresentam algum tipo de problema sejam em não atender às especificações da encomenda ou aqueles que apresentam erros conceituais ou técnicos, são descartados. Portanto, aqueles Itens que não foram descartados, são aprovados e, a CAA indica, dentre esses aprovados, aqueles que serão inseridos no BNI-ENADE e os que serão selecionados e farão parte da prova do ENADE daquela edição. Assinala-se que os Itens aprovados são remunerados. Por estes Itens aprovados são pagos aos seus elaboradores e revisores o valor unitário do Item. Com isso, os Itens aprovados passam a ser propriedade do INEP. Os descartados, não serão utilizados e, portanto, não são remunerados os seus elaboradores e revisores.

Uma vez concluída esta etapa, a Comissão de Assessoramento Técnico (CAT), junto à equipe de servidores da CGENADE, atuam na revisão de sensibilidade e de língua portuguesa dos Itens que comporão as provas, com vistas a identificar e corrigir possíveis controvérsias e outros problemas nos Itens que foram aprovados pelas CAA para a composição da prova. A CAT, nomeada a cada ano em portaria específica, é constituída por um grupo de docentes especialistas no trabalho com exames de larga escala, que acompanha várias etapas do processo de elaboração dos instrumentos avaliativos. Após essa etapa, a equipe de servidores da CGENADE realiza a revisão final, etapa que antecede a homologação dos Itens aprovados no BNI.

De acordo com Soares; Hora; Caseiro (2016), após essa maratona de procedimentos, é posto então, para a apreciação da CAT, os procedimentos finais no ambiente do BNI-ENADE. Após revisão, e homologação dos Itens, a CAT realiza a adaptação e singularidades 
específicas de estudantes com necessidades especiais. Por fim, "[...] a equipe técnica do INEP aprova e libera todas as provas e os materiais técnico-administrativos para a impressão e montar o gabarito preliminar que será divulgado após a aplicação do Exame" (SOARES; HORA; CASEIRO, 2016, p. 8-9).

Portanto, pode-se observar que há uma sequência lógica e adequada para os procedimentos necessários ao refinamento e lapidação de um Item para compor a prova do ENADE. Todas essas etapas estão previstas baseando-se nos princípios da segurança e qualidade do instrumento de avaliação da educação superior.

\section{ANÁlise de RESUltados e PROPOSTAS de INTERVENÇÕes PEDAGÓGICAS PARA O BNI-ENADE}

Elucidadas as etapas de tratamento e abastecimento do BNI-ENADE com Itens provenientes daquela edição do ENADE, é proposta uma reflexão e avaliação de todos os processos e etapas concluídas. Com isso, é possível propor novas intervenções que possam corrigir ou mesmo agregar novos conhecimentos que tragam melhorias aos processos. E, com isso, novas metodologias podem surgir e trazer melhorias aos instrumentos de avaliação da Educação Superior. A seguir são postas algumas dessas avaliações e reflexões que foram realizadas ao longo das edições desse exame.

Com a implantação desse sistema de avaliação da Educação Superior, foi observada a ampliação da participação da comunidade acadêmica na construção dos instrumentos, respeitando os princípios estabelecidos pela lei de criação do SINAES. Como pôde ser notada, a construção de um acervo de Itens com qualidade técnica, pedagógica e psicométrica, capazes de alcançar com precisão a proficiência dos estudantes em relação aos aspectos previstos nas DCNs dos cursos de graduação do país. Um processo continuado de melhoria no fluxo de processo com inclusão de novas etapas, tais como: revisão final, realizada pela CAA e revisão de sensibilidade, realizada pela CAT (CERRI, 2016). 
A tabela 1 apresenta o quantitativo de Itens elaborados, aceitos e descartados por modalidade (Bacharelado, Tecnológico e Formação Geral), na edição do ENADE 2019.

Tabela 1 - Índice de aproveitamento do BNI-ENADE 2019

\begin{tabular}{c|c|c|c|c}
\hline \multicolumn{5}{c}{ APROVEITAMENTO DO BNI-ENADE EM 2019 } \\
\hline MODALIDADE & ELABORADOS & ACEITOS & DESCARTES & $\begin{array}{c}\text { APROVEITAMENTO } \\
\mathbf{( \% )}\end{array}$ \\
\hline Bacharelado & 3.542 & 2.310 & 1.232 & 65 \\
\hline Tecnológico & 883 & 480 & 403 & 54 \\
\hline $\begin{array}{c}\text { Formação } \\
\text { Geral }\end{array}$ & 58 & 29 & 29 & 50 \\
\hline Total & 4.483 & 2.819 & 1.664 & 63 \\
\hline
\end{tabular}

Fonte: INEP (2021).

Conforme já anunciado, neste trabalho optou-se pelo manuseio de números inteiros, uma vez que se trata de números inteiros de Itens. Ademais, o aproveitamento, neste caso, se traduz em números de Itens aceitos e, portanto, não haverá prejuízos significativos em proceder com o aproveitamento em porcentagem em números inteiros. O resultado do aproveitamento total aponta para um número satisfatório, levando em consideração de que, para cada prova, são utilizados 40 Itens, sendo 30 Itens de Conhecimentos Específicos e 10 Itens de Formação Geral. Contudo, é necessário estar atento ao abastecimento do BNI-ENADE e desenvolver propostas contínuas de aprimoramento nos processos de capacitação para que os resultados não sofram declínio.

Em relação à distribuição dos Itens apontados na tabela 1 e aos cursos do ciclo do ENADE de 2019, os gráficos e as tabelas a seguir, dão conta de como se dá a distribuição em termos de quantidade e qualidade. É possível inferir que o processo de abastecimento do BNI-ENADE ocorre de forma dinâmica e contínua, de tal modo que, as metodologias utilizadas nos cursos de capacitação dos colaboradores, têm ocorrido de forma positiva e não se configuram de um processo pronto e acabado. Com isso, ratifica-se a necessidade de manutenção e continuidade dos processos de melhorias na formação cada vez mais atualizadas dos colaboradores. No quadro 2 são 
apresentados os 29 cursos avaliados na edição do ENADE de 2019 e a área de Formação Geral.

Quadro 2 - Cursos avaliados e área de Formação Geral - ENADE 2019

\begin{tabular}{|l|l|}
\hline \multicolumn{2}{|c|}{ CURSOS AVALIADOS E ÁREA DE FORMAÇÃO GERAL - ENADE 2019} \\
\hline 1. Agronomia & $\begin{array}{l}\text { 16. Engenharia de Controle e } \\
\text { Automação }\end{array}$ \\
\hline 2. Arquitetura e Urbanismo & 17. Engenharia de Produção \\
\hline 3. Biomedicina & 18. Engenharia Elétrica \\
\hline 4. CST em Agronegócio & 19. Engenharia Florestal \\
\hline 5. CST em Estética e Cosmética & 20. Engenharia Mecânica \\
\hline 6. CST em Gestão Ambiental & 21. Engenharia Química \\
\hline 7. CST em Gestão Hospitalar & 22. Farmácia \\
\hline 8. CST em Radiologia & 23. Fisioterapia \\
\hline 9. CST em Segurança no Trabalho & 24. Fonoaudiologia \\
\hline 10. Educação Física & 25. Formação Geral \\
\hline 11. Enfermagem & 26. Medicina \\
\hline 12. Engenharia Ambiental & 27. Medicina Veterinária \\
\hline 13. Engenharia Civil & 28. Nutrição \\
\hline 14. Engenharia de Alimentos & 29. Odontologia \\
\hline 15. Engenharia de Computação & 30. Zootecnia \\
\hline
\end{tabular}

Fonte: INEP (2021).

No gráfico 1 a seguir estão apresentados os dados referentes aos números de Itens elaborados, aceitos e descartados para cada curso avaliado na edição do ENADE de 2019.

Gráfico 1 - Número de Itens elaborados, aceitos e descartados por curso ENADE 2019

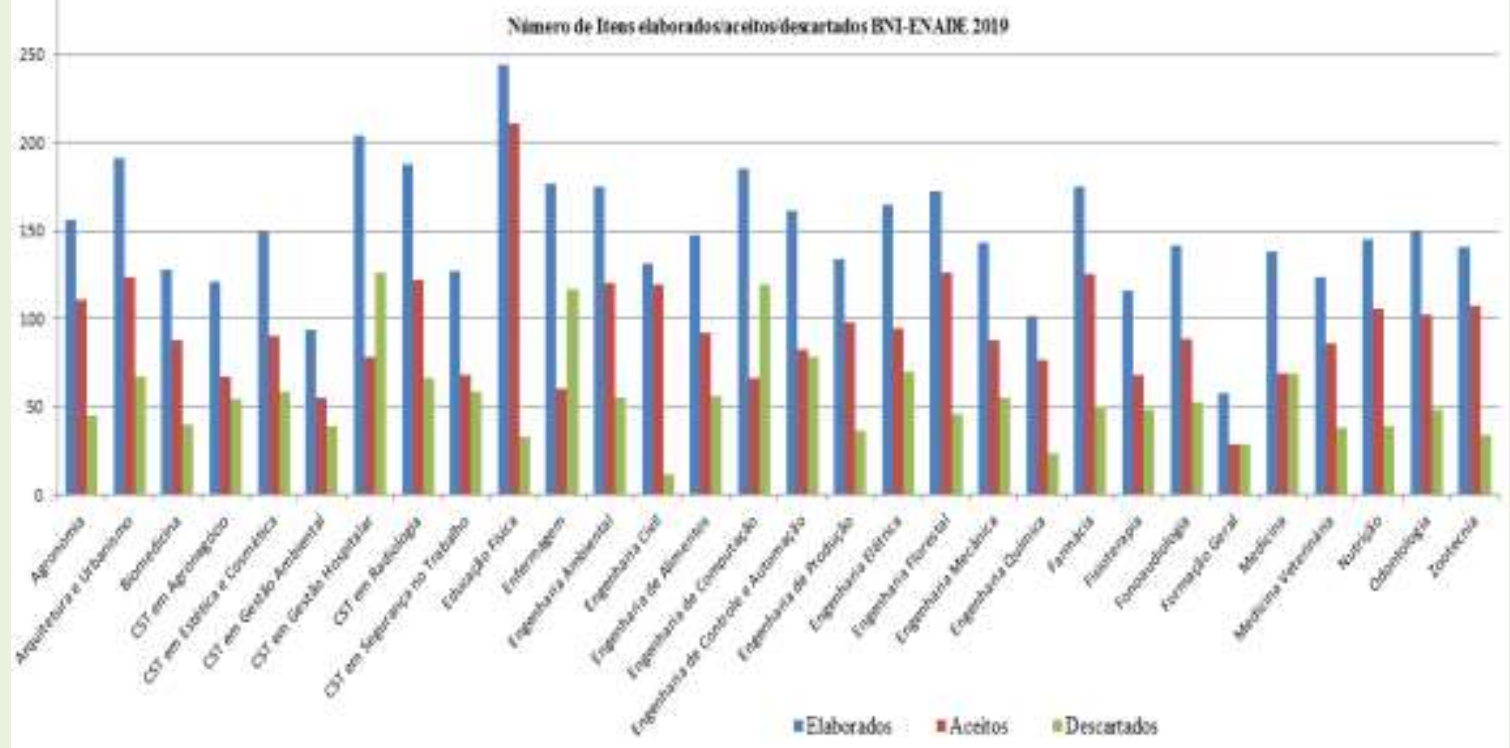

Fonte: INEP (2021). 
Os dados apresentados no gráfico mostram que para a maioria dos cursos, é produzido pelo menos três vezes o número de Itens exigidos para comporem a prova de cada curso. Com isso, percebe-se o que se tem discutido ao longo deste trabalho: êxitos nas ações afirmativas dos cursos de capacitação dos elaboradores e revisores de Itens para alguns cursos e áreas; necessidade de continuidade de aprimoramentos nos processos pedagógicos e; a ratificação de que as premissas desses processos de abastecimento do BNI-ENADE têm sido em uma trajetória de resultados promissores.

Para todos os cursos avaliados nesta edição do ENADE foram aprovados (aceitos) um número de Itens que é maior que 30. Isso significa que, subtraído o número de Itens que comporão a prova, os demais serão inseridos no BNI-ENADE, gerando um saldo positivo neste banco para todos os cursos avaliados nesta edição do ENADE. Ou seja, há de fato evidências de resultados positivos em função de ações afirmativas assinaladas nos cursos de capacitação para elaboradores e revisores de Itens. Pode-se verificar que, de fato, há necessidade na continuidade de aprimoramentos nos processos pedagógicos de treinamentos e capacitação dos colaboradores. Contudo, percebe-se que o abastecimento do BNI-ENADE de Itens aprovados tem apresentado resultados satisfatórios, embora em alguns cursos ou áreas, ainda, apresentem uma carência de Itens com qualidade suficiente para compor o BNI-ENADE.

Os dados apresentados neste gráfico sinalizam para números alarmantes de Itens descartados em determinados cursos, como por exemplo, no curso de Enfermagem, CST - Gestão Hospitalar e Engenharia de Computação. O alerta sinaliza para dificuldades de docentes destas áreas em elaborar Itens que atendam ao padrão exigido pelo INEP para que eles componham o BNI-ENADE. Por outro lado, ratifica-se a afirmativa de que a capacitação pedagógica se faz ainda necessária no processo de elaboração e revisão de Itens, não só em função de novos componentes desse grupo de docentes, mas também pela necessidade de novas investidas de intervenções pedagógicas nesse processo. Embora o BNI- 
ENADE esteja em uma fase de pleno abastecimento de Itens, ainda, não tendo apresentado indícios de colapso no sentido de carência generalizada de Itens, é preciso estar atento para essa possibilidade no futuro próximo.

Os principais motivos pelos quais Itens são descartados pelos membros das CAAs e pela equipe da CGENADE/INEP, estão apresentados no quadro 3.

Quadro 3 - Motivos de descartes de Itens para o BNI-ENADE

\begin{tabular}{|c|c|}
\hline \multicolumn{2}{|c|}{ PRINCIPAIS MOTIVOS DE DESCARTES DE ITENS DO BNI-ENADE } \\
\hline MOTIVO & JUSTIFICATIVA \\
\hline Implausibilidade. & $\begin{array}{l}\text { Distratores que favoreçam a resolução mediante } \\
\text { raciocínio por exclusão. }\end{array}$ \\
\hline Nível de dificuldade. & $\begin{array}{l}\text { Aquém do adequado ou muito simples/óbvio para } \\
\text { avaliar concluintes de cursos de graduação. }\end{array}$ \\
\hline $\begin{array}{l}\text { Abordagem } \\
\text { conhecimento. }\end{array}$ & $\begin{array}{l}\text { Muito específico; mais próximos das linhas } \\
\text { especializadas de pesquisa na pós-graduação. }\end{array}$ \\
\hline $\begin{array}{l}\text { Uso de } \\
\text { estatísticos. }\end{array}$ & $\begin{array}{l}\text { Informações (centrais, conceitos, abordagem } \\
\text { teórica) defasadas, ultrapassadas ou controversas } \\
\text { que comprometem a validade das afirmações. }\end{array}$ \\
\hline Construções textuais. & $\begin{array}{l}\text { Elaborada em língua estrangeira para prova em } \\
\text { que não cabe a adoção de outro idioma. }\end{array}$ \\
\hline Jção c & $\begin{array}{l}\text { Idêntico ou extremamente semelhante a outro que } \\
\text { já foi selecionado para o BNI. }\end{array}$ \\
\hline $\begin{array}{l}\text { ça } \\
\text { alismos. }\end{array}$ & $\begin{array}{l}\text { Falta de abrangência mínima correspondente ao } \\
\text { caráter nacional do Exame. }\end{array}$ \\
\hline $\begin{array}{l}\text { Ocorrência de falhas } \\
\text { técnicas ou fuga do } \\
\text { modelo proposto pelo } \\
\text { INEP para as provas do } \\
\text { ENADE. }\end{array}$ & $\begin{array}{l}\text { Item solicita a escolha de opção incorreta. } \\
\text { Item de asserção-razão fora do padrão. } \\
\text { Item apresenta redação sem coesão e/ou } \\
\text { coerência entre os elementos, estando, no todo, } \\
\text { prejudicado. } \\
\text { Item apresenta distratores excludentes entre si. } \\
\text { Item apresenta distratores óbvios, que não } \\
\text { dependem de formação em curso de graduação } \\
\text { para serem julgados. } \\
\text { Item depende de análise } \\
\text { gráfico/imagem/tabela que está ausente. }\end{array}$ \\
\hline $\begin{array}{lr}\text { Item } & \text { apresenta } \\
\text { problemas } & \text { de } \\
\text { sensibilidade, estando, } \\
\text { no todo, prejudicado. }\end{array}$ & $\begin{array}{l}\text { Item aborda o tema de forma preconceituosa. } \\
\text { Item apresenta problemas relacionados a questões } \\
\text { político-partidárias. }\end{array}$ \\
\hline Falta correspondência com a & $\begin{array}{l}\text { Encaminhamento de item discursivo ao invés de } \\
\text { item de múltipla escolha/objetivo. }\end{array}$ \\
\hline
\end{tabular}

Fonte: Elaborado pelo autor. 
A tabela 3 apresenta, de forma já esclarecida, a eficiência do BNIENADE para cada curso e área dessa edição do ENADE.

Tabela 3 - Eficiência de Itens do BNI-ENADE 2019

\begin{tabular}{l|c}
\hline \multicolumn{2}{c}{ EFICIÊNCIA DO BNI-ENADE EM 2019 POR CURSO E ÁREA } \\
\hline \multicolumn{1}{c}{ CURSO/ÁREA } & EFICIÊNCIA (\%) \\
\hline 1. Agronomia & 52 \\
\hline 2. Arquitetura e Urbanismo & 49 \\
\hline 3. Biomedicina & 45 \\
\hline 4. CST em Agronegócio & 31 \\
\hline 5. CST em Estética e Cosmética & 40 \\
\hline 6. CST em Gestão Ambiental & 27 \\
\hline 7. CST em Gestão Hospitalar & 24 \\
\hline 8. CST em Radiologia & 49 \\
\hline 9. CST em Segurança no Trabalho & 30 \\
\hline 10. Educação Física & 74 \\
\hline 11. Enfermagem & 17 \\
\hline 12. Engenharia Ambiental & 51 \\
\hline 13. Engenharia Civil & 68 \\
\hline 14. Engenharia de Alimentos & 42 \\
\hline 15. Engenharia de Computação & 19 \\
\hline 16. Engenharia de Controle e Automação & 33 \\
\hline 17. Engenharia de Produção & 51 \\
\hline 18. Engenharia Elétrica & 39 \\
\hline 19. Engenharia Florestal & 56 \\
\hline 20. Engenharia Mecânica & 41 \\
\hline 21. Engenharia Química & 47 \\
\hline 22. Farmácia & 54 \\
\hline 23. Fisioterapia & 33 \\
\hline 24. Fonoaudiologia & 42 \\
\hline 25. Formação Geral & 33 \\
\hline 26. Medicina & 28 \\
\hline 27. Medicina Veterinária & 45 \\
\hline 28. Nutrição & 52 \\
\hline 29. Odontologia & 48 \\
\hline 30. Zootecnia & 55 \\
\hline & 43 \\
\hline
\end{tabular}

Fonte: INEP (2021).

Em tese, cursos que têm o número de Itens aceitos maior que o número de Itens necessários para comporem a prova daquela edição, possuem cenários positivos em relação ao BNI-ENADE. Ainda assim, cursos 
com eficiência com porcentagens nula ou negativa requerem uma atenção maior no que se refere ao abastecimento do BNI-ENADE, o que não ocorreu nesta edição do BNI-ENADE. Esse alerta se justifica em função do fluxo de inserção e retirada de Itens para a composição da prova. Portanto, é fundamental que se mantenha a atenção caso haja ocorrência desse fato com algum curso ou área de Formação Geral. Como já salientado, independente de fatores de risco de desabastecimento do BNI-ENADE, a de se concentrar esforços no sentido de manter um número razoável e confortável de ltens nesse banco.

Nesta edição da prova ENADE os cursos de Biomedicina e Engenharia Mecânica tiveram o mesmo número de Itens aceitos, 88. Embora houvesse a inserção de 58 itens para cada um deles no BNI-ENADE, considerando que 30 Itens foram selecionados para a prova, as eficiências foram de $45 \%$ e $41 \%$, respectivamente. Outra ocorrência interessante foi entre os cursos de Engenharia Ambiental e Engenharia de Produção, na qual ambos tiveram a mesma eficiência, 51\%. Porém, o primeiro teve a inserção de 90 Itens no banco e o segundo 68 Itens no banco. Estas ocorrências estão relacionadas ao fato de que para o cálculo da eficiência o número de Itens elaborados é levado em consideração, conforme demonstrado na equação da página 3. Por fim, para esta edição da prova ENADE, a eficiência total foi de $43 \%$.

Tendo em vista essas discussões e análises avaliadas como pertinentes, algumas intervenções pedagógicas podem contribuir com esse fluxo de Itens no BNI-ENADE, de tal modo que, o fluxo de entrada de Itens seja maior que o fluxo de saída de Itens desse banco. Deve-se levar em consideração que, em função da produção de novos conhecimentos, alguns Itens desse banco podem se tornar obsoletos. Outro fator que pode interferir nessa "validade" de Itens é a atualização nos sistemas normativos, que podem trazer transtornos a Itens que levam em consideração normas específicas da área e/ou normas gerais, além das reformas que acontecem no sistema educacional superior do país.

Uma primeira intervenção pedagógica seria a constituição de uma equipe de docentes de cada curso e/ou área de conhecimento para uma 
análise detalhada de todo o conteúdo de Itens contidos no BNI-ENADE, para que, assim, se possa ter uma leitura precisa do quantitativo de Itens que há em perfeitas condições de uso. Com isso, poderia se efetivar uma "limpeza" do banco tendo um real conhecimento da situação dos Itens armazenados nesse banco.

Uma segunda intervenção pedagógica seria a efetivação do curso de capacitação no formato contínuo, iniciando pelos cursos e/ou áreas que estão em maior risco de abastecimento de seus respectivos armazenamentos de Itens. Além desse propósito, atenderia também à agenda dos professores, pois muitas das vezes, suas participações nos processos de elaboração de Itens são prejudicadas em função de suas atuações na docência nos referidos cursos.

Por último, poderia se criar um canal com grupos de IES para atendimentos em formatos de encontros, simpósios, workshops, webinários, dentre outros, para esclarecimentos e orientações dos procedimentos necessários para a construção de Itens de qualidade. Com isso, poder-se-ia atrair mais participantes nos processos de elaboração de Itens para o BNIENADE, com possiblidades reais de aumento da eficiência desse banco de Itens.

\section{CONSIDERAÇÕES FINAIS}

Na elaboração deste trabalho, a análise e a interpretação de dados oficiais disponibilizados pelo INEP possibilitou uma análise descritiva numa visão qualitativa e quantitativa. As evidências apontaram para uma expectativa inicial de que, esses dados e informações, retratassem de fato a realidade do BNI-ENADE em 2019. Com isso, ao efetuar comparações entre as eficiências dos cursos e área, foi possível identificar a problemática da eficiência em alguns cursos.

Por conseguinte, levou-nos ao questionamento: que medidas pedagógicas podem ser sugeridas e/ou adotadas, nos cursos de capacitação oferecidos pela Coordenação Geral do ENADE (CGENADE) do INEP aos docentes elaboradores de Itens, para contribuir com melhorias na 
eficiência do BNI-ENADE, o que pôde-se averiguar a partir das análises de dados disponibilizados pelo INEP. Dentro dessa problemática, foi possível atingir o principal objetivo deste estudo: propor medidas pedagógicas que possam trazer melhorias no aproveitamento de Itens para o BNI-ENADE.

As medidas que vêm sendo adotas pela gestão do BNI-ENADE através da Diretoria de Avaliação da Educação Superior (DAES) do INEP, demonstram um esforço no sentido de atender as necessidades de abastecimento desse banco de Itens. As medidas adotadas, na opção em estender esse abastecimento, as chamadas públicas têm contribuído para um número cada vez maior de colaboradores nos processos de elaboração e revisão de Itens.

Por fim, considera-se que este estudo apresentou sua linha de contorno nos limites de dados apresentados pelo órgão responsável pelo BNI-ENADE. Nesse sentido, dificuldades na comparação com outras fontes de dados nos períodos pertinentes, como por exemplo, as variáveis ora analisadas que não têm as mesmas conotações, sendo definidas de modo arbitrário conforme a conveniência do estudo, como taxa de eficiência de Itens do BNI-ENADE, por exemplo. Assim, estudos futuros poderiam aprofundar ou mesmo dar novas dimensões de análises pertinentes sobre a comparabilidade com outras edições do ENADE; custo efetivo dos processos do BNI-ENADE e, assim, estender o entendimento da problemática de demanda do aumento de Itens aceitos (aprovados) para esse banco de Itens. Além disso, apontar outros meios que venham a contribuir com essa eficiência ou deficiência de Itens de qualidade para compor o BNI-ENADE.

\section{REFERÊNCIAS}

BRASIL. Casa Civil. Lei ${ }^{\circ}$ 10.861, de 14 de abril de 2004. Institui o Sistema Nacional de Avaliação da Educação Superior - SINAES. Disponível em: http://www.planalto.gov.br/ccivil_03/_ato2004-2006/2004/lei/l10.861.htm. Acesso em: 10 mai. 2019.

BRASIL. Ministério da Educação. Portaria n².051, de 9 de julho de 2004. Disponível em: http://portal.mec.gov.br/arquivos/pdf/Portaria\%20n\%C2\%BA\%202051.pdf. Acesso em: 12 de set. 2019. 
BRASIL. Ministério da Educação. Cadastro do BNI. Disponível em: http://portal.mec.gov.br/component/tags/tag/35017-banco-nacional-deitens. Acesso em 11: de jul. 2020.

CAMPOS, F. C. S. Elaboração da prova do ENADE e no modelo do banco nacional de itens. Dissertação (Mestrado), Programa de pós-graduação profissional em gestão e avaliação da educação pública. Área de concentração: Centro de Políticas Públicas e Avaliação da Educação. Faculdade de Educação - CAEd/UFJF. Juiz de Fora - MG, 2013.

CERRI, R. Palestra na PUC-Campinas: BNI ENADE. Disponível em: https://www.puc-campinas.edu.br/wp-content/uploads/2016/04/proavipalestra-sobre-bni-seminarios-enade2014.pdf. Acesso em: 13 de jun. 2019.

INEP. Edital de chamada pública. Cadastro de elaboradores e revisores de Itens da Educação Superior (Ceres) do Banco Nacional de Itens da Educação Superior (BNI - ES). Brasília: INEP. 2019.

INEP. ENADE. Disponível em: http://portal.inep.gov.br/enade. Acesso em: 11 de ago. 2019.

INEP. Guia BNI. Disponível em: http://inep.gov.br/guia-bnil. Acesso em: 10 de jul. 2019.

INEP. Guia BNI - atualizado em 19 de fevereiro de 2020. Disponível em: http://inep.gov.br/guia-bni1. Acesso em: 10 de mai. 2020.

INEP. Guia BNI - DAEB. Guia de elaboração e revisão de Itens. v. 1. Brasília: INEP, 2010.

INEP. O que é o BNI. Disponível em: http://inep.gov.br/banco-nacional-deitens. Acesso em: 11 de jul. 2019.

INEP. O que é o ENADE. Disponível em: http://portal.inep.gov.br/enade. Acesso em: 11 de ago. 2019.

INEP. Produção de Itens para prova ENADE. Manifestação Protocolo: $n^{\circ}$ 23546.025418/2021-09. Brasília: INEP, 2021.

SOARES, M. N. T.; HORA, P. M.; CASEIRO, L. O Banco Nacional de Itens do ENADE: iniciativa para democratização e avanços nos processos da avaliação da Educação Superior. $2^{\circ}$ Simpósio Avaliação da Educação Superior. Porto Alegre, 2016.

Recebido em: 17 de julho de 2021. Aprovado em: 11 de agosto de 2021. Publicado em: 17 de setembro de 2021. 